\title{
Selection of renewable energy technologies for Africa: Eight case studies in Rwanda, Tanzania and Malawi
}

\author{
Marie-Louise Barry ${ }^{\mathrm{a}, *}$, Herman Steyn ${ }^{\mathrm{a}}$, Alan Brent ${ }^{\mathrm{b}}$ \\ ${ }^{a}$ Graduate School of Technology Management, University of Pretoria, Lynwood Road, Pretoria 0002, South Africa \\ ${ }^{\mathrm{b}}$ Centre for Renewable and Sustainable Energy Studies, School of Public Leadership, Stellenbosch University, 7600, South Africa
}

\section{A R T I C L E I N F O}

\section{Article history:}

Received 2 October 2010

Accepted 11 April 2011

Available online $\mathrm{xxx}$

\section{Keywords:}

Renewable energy systems

Technology selection

Case studies

Africa

\begin{abstract}
A B S T R A C T
Renewable energy technologies need to be implemented to improve the current lack of access to energy on the African continent. However, the implementation of renewable energy technologies in Africa often fails, or the technologies are found to be unsustainable in the longer term. Previous research determined eleven factors that should be taken into account for the selection of sustainable, renewable energy technologies in Africa. The purpose of this research was to confirm and build upon these findings by means of eight case studies that were conducted in Rwanda, Tanzania and Malawi. Various individuals from implementing agencies, as well as end users of the various technologies, were interviewed, while secondary data were gathered in the form of project reports and other documentation. The analyses of the data confirm the importance of the eleven factors that were previously identified. A final set of thirteen factors that should be used for the selection of renewable technologies are proposed.
\end{abstract}

() 2011 Elsevier Ltd. All rights reserved.

\section{Introduction}

The majority of the population in sub-Saharan Africa lives in rural areas and most of the people spend $5 \%-20 \%$ of their monthly income on fuel [1]. Currently, 23.6\% of the total population in region have access to electricity while only $8.4 \%$ of people in rural areas have access to electricity.

The use of renewable energy resources is advocated to improve this situation because: renewable energy technologies are modular and require low initial investment, which can be incrementally expanded; the use of renewable energy technologies would imply less dependence on fossil-based fuels, which need to be imported in most cases and are subject to external price fluctuations; and the diversification of energy generation contributes to energy security provided that efficient, affordable and cost effective technologies are selected [2]. Furthermore, since renewable energies are those obtained from a natural, recurring and continuous outflow of energy in the existing natural environment, they have the obvious advantage of inherent sustainability and the absence of carbon emissions [2].

The general success rate of World Bank financed electric power projects is $68 \%$, while the success rate of such projects in the subSaharan Africa region is estimated to be only $36 \%$ [3]. The authors

\footnotetext{
* Corresponding author. Tel.: +27 12420 4605; fax: +27 123625307.

E-mail address: mlb@up.ac.za (M.-L. Barry).
}

believe that one of the reasons for this low success rate is that the factors that need to be taken into account during the selection of a renewable energy technology in Africa have not been investigated in depth.

\section{The state of technology development in Africa}

Technology management in developing countries is very different from that in developed countries. In developed countries the emphasis is on the control and utilisation of technology, as well as offsetting the undesirable consequences of technology. In developing countries on the other hand, because of the lack of skilled resources, the emphasis is on technology selection and transfer to achieve rapid economic and social development [4]. Technology transfer for sustainable development has, however, failed to meet expectations [5].

Various authors discuss the factors for the selection of sustainable energy technologies in developing countries and some authors discuss some of the special characteristics for the selection of technologies in Africa.

According to the findings of Teitel [6], in his study on the selection of appropriate technologies for less industrialised countries, some industrial technologies are inappropriate because of "inadequate response to market requirement; failure to use and or adapt to the local supply of materials; failure to adapt to a smaller scale of production; insufficient use of labour because of price distortions and other restrictions; import of unsuitable machinery; 
and selection of unsuitable technology because of restriction on the acquisition of technology". Teitel [6] further states that the top three reasons for mal-adaptation of technology in developing countries are maintenance and repair complexities; obsolescence of components; and the fact that the technology has not been adapted to the climate.

According to Dunmade [3] the primary factor of sustainability of a technology is adaptability of the technology whereas the secondary factors include technical sustainability, socio-political sustainability, environmental sustainability, and economic sustainability.

The SURE model proposed by Cherni [7], for the calculation of energy options for rural communities and tested in a Columbian rural community, uses a multi-criteria decision support system and includes the following factors - physical resources including houses and roads; human resources such as skills and education; financial resources including wages and savings; social resources such as networks and social organisations; and natural resources including land and water resources [7].

The selection and evaluation of emerging technologies is more complicated because of the inherent uncertainty and ambiguity of emerging technologies [8]; many renewable energy technologies are deemed emerging technologies.

Africa is also an emerging economy, so the introduction of new technologies is further complicated. The translation of research knowledge in and of Africa into economic and social benefits is very complex [9]. The complexity of the technology selection problem grows as the number of factors and the number of alternatives to consider increases [10]. The lack of skilled resources creates great difficulties in Africa. These difficulties are experienced by the implementing organisations, governments and users. Countries in Africa do not have the institutional capacity to implement effective environmental policies; this is mainly because building institutional capacity involves the development of material and human resources and Africa does not have skilled human resources [11]. Consumers in Africa do not easily accept renewable energy technologies because they lack knowledge about the advantages and opportunities for using these types of technologies [12]. Other realities in Africa, such as poverty alleviation, can derail the implementation of renewable energies as conventional energy implementation is cheaper in the short term [12]. When renewables are first implemented, training and knowledge transfer needs to take place which means that resources, capital and time need to be expended [13].

In order to overcome these difficulties in Africa it is important that training and education of communities, especially the poor, are undertaken before technologies are implemented [1,2]. Training and skills development of communities will alleviate the lack of user acceptance and also ensure that the skills base of the community can be improved to help maintain the technology [12]. It is important that governments create consumer awareness through information programmes to educate the potential users on the advantages of renewable energy technologies [14]. Training of personnel and setting of technical standards also help overcome the difficulties of the general lack of skills in Africa [2].

Government participation and support, including institutional and political frameworks, are essential for the success of implementation of sustainable, renewable energy technologies in Africa. The technology selected must impact on both the priorities of the local population, as well as on the social and environmental targets of the government [15]. Government needs to establish appropriate legal and regulatory frameworks that support the implementation of renewable energy technologies [12]. Government further needs to derive policies and strategies that reflect the willingness of government to support technologies through, for example, subsidy schemes [12]. Government can also encourage the uptake of renewable energy technologies by removing taxes and duties to exempt components or such technologies that are imported and establish a specialised agency to plan and promote renewable energy technologies, amongst others [14].

When implementing renewable energy technologies in informal rural communities the commonly used economic measures of development and wealth are not applicable as these measures do not make allowance for cash income, payment in kind or the provision of basic services by government [15]. The initial and operational costs of renewable energy technologies should be subsidised by government or donor agencies to ensure that renewable energy technologies can compete with conventional technologies [12]. Up front communication with the community about the costs associated with the use of electricity also contributes to success of implementation [1]. Renewable energy projects should be shown to improve the life of the poor through job creation in rural communities [12].

The involvement of the community has also been shown to be especially important for the success of renewable energy technology implementation. Innovative energy products first reach the early adopters who have a visionary attitude and will adopt the innovation. An innovation chasm then exists in which the innovation does not reach the rest of the population. It is suggested that mainstream members of housing associations should be persuaded to adopt energy conservation innovations to ensure that the innovations reach the rest of the population [16]. Support from the community of renewable energy projects is also needed to avoid theft [1].

Previous research of Barry et al. [17,18] has determined eleven factors that should be taken into account for the selection of sustainable, renewable energy technologies in Africa as shown in Table 1 . The eleven factors take all of the abovementioned issues, and others, into account. The categorised list of factors serves as the theoretical basis for this study.

The purpose of the case studies reported in this paper was to determine whether the previous research has indeed identified all the main factors. The multiple-case method advocated by Yin [19] was used in this study. It is beneficial to consider more than one case when conducting case study research as this leads to the possibility of easily replicating case studies and improves generalisability [19]. For this reason it was decided to select renewable technology implementations in three countries in sub-Saharan

Table 1

Eleven main factors that need to be considered for renewable energy technology selection in Africa.

\begin{tabular}{ll}
\hline Abbreviation & Description \\
\hline T & Technology factors \\
T1 & $\begin{array}{l}\text { Ease of maintenance and support over the life cycle } \\
\text { of the technology } \\
\text { Ease of transfer of knowledge and skills to relevant } \\
\text { people in Africa }\end{array}$ \\
T2 & Site selection factors \\
SS & Local champion to continue after implementation \\
SS1 & Adoption by community \\
SS2 & Suitable sites ready for pilot studies \\
SS3 & Access to suitable sites can be secured \\
SS4 & Economic/financial factors \\
E & Economic development \\
E1 & Availability of finance \\
E2 & Achievability by performing organisation \\
A & Project management \\
A1 & Financial capacity \\
A2 & Technological capacity \\
A3 &
\end{tabular}

(Source: Barry et al. $[17,18]$ ) 
Africa namely Rwanda, Tanzania and Malawi, as access could be gained to the entities involved in these implementations. The specific cases were diverse enough to satisfy the requirements of the case study research methodology, as shown in Table 2.

Different types of renewable energy implementations where considered, namely: household and institutional biogas in Rwanda; solar energy, domestic biogas, efficient stoves and efficient ovens in Tanzania; and efficient stoves and efficient tobacco barns in Malawi. A different implementation model was followed in each of the cases. In Rwanda a donor agency (SNV) did the implementation with support from the government; in Tanzania the implementation was done by a non-government aid agency; and in Malawi the implementation was driven by the government with support from the Programme for Basic Energy and Conservation (ProBEC).

Rwanda is a small poor rural third world country in Africa and is landlocked by Democratic Republic of Congo (DRC), Uganda, and Tanzania. With a population of 10 million people, Rwanda is the most densely populated country in Africa and $90 \%$ of the population is engaged in agricultural activities [20].

The energy need of $94 \%$ of Rwandese is met by biomass which is made up of combustible wood and vegetal residue [21]. The current production of electricity is dependent on hydro schemes, which are susceptible to droughts and there have been prolonged periods of drought in Rwanda in the last 20 years [21].

One of the goals of the government's National Adaption Program of Action (NAPA) is the reduction of wood energy utilisation form $94 \%-60 \%$ by 2010 and to $50 \%$ in 2020 [21]. NAPA has identified the low capacity of human and financial resources, focussing on hydroelectricity to the exclusion of mixed solutions and resistance to change as the main risks for this programme.

Two case studies were selected in Rwanda namely the domestic biogas programme and the institutional biogas programme. One of the projects started by the Ministry of Infrastructure (MININFRA) to support NAPA is the National Domestic Biogas Program (NDBP). The goal of the NDBP is to implement 15,000 biogas plants for Rwandan households with two to three zero grazing cows (i.e. cows kept in a pen) by December 2011 [22].

Twenty eight biogas systems have been installed in institutions in Rwanda since 2001 while another eight are under construction. Of the total of 36 units, thirteen were installed in secondary schools, eleven in prisons, seven in community households, two in military camps, two in training centres and one in a hospital [23].

Tanzania is situated in east Africa. The borders of the country include the Indian Ocean, Kenya, Uganda, Rwanda, Burundi, the
Democratic Republic of Congo, Zambia, Malawi and Mozambique [24]. Tanzania has a population of more than 40 million people and $80 \%$ of the population is involved in agricultural activities [24].

The main source of electricity in Tanzania is hydro-electric plants with over $90 \%$ of the energy in Tanzania coming from hydro [24] with thermal plants providing for peak loads [25]. In terms of household energy consumption, $97.7 \%$ of all household energy for cooking, heating and lighting derives from biomass [26].

Four case studies were selected in Tanzania namely domestic biogas technology, solar energy, efficient stoves and efficient ovens. A study was done by Mwakje [26] regarding the opportunities and constraints of biogas use in the Rungwe district in south west Tanzania. The history of biogas in Tanzania started in 1975 when the small industries development organisation constructed 120 floating drum plants in Arusha. At the end of 1989, 200 biogas plants had been installed all over Tanzania and in 1992 this increased to 600 plants. No further figures are given from 1992 to the present.

The solar energy case study is being implemented by Tanzania Traditional Energy Development and Environmental Organisation (TaTEDO), a non-governmental organisation (NGO) based in Tanzania that specialises in the development of sustainable modern energy services for Tanzanian residents [27]. The main goals of TaTEDO are: to improve the quality of life of Tanzanians by facilitating access to modern energy services; to minimise harm to the environment and to contribute to the reduction of Tanzania's dependence on imported energy [27].

The efficient stove case study is also being implemented by TaTEDO. The project involves the construction of stoves in Hai and Rombo districts in Tanzania. The aim is to install stoves for 6000 to 10000 household over 2 years. The efficient oven case study is also being implemented by TaTEDO. There are more than 200 small scale bakers using the improved TaTEDO charcoal ovens.

The Republic of Malawi is a small country in southern Africa. It shares borders with Zambia, Tanzania and Mozambique [28]. Malawi is one of the least developed countries in the world, ranking 168 out of a total of 174 countries [29] and more than $90 \%$ of the export revenue of the country comes from agricultural products.

The deforestation rate in Malawi is $2.8 \%$ per year and is the highest in Africa which is contributed to by the fact that $95 \%$ of Malawi's primary energy supply and $90 \%$ of total energy is from biomass, mainly in the form of firewood and charcoal [29].

The Department of Energy Affairs in Malawi is working with the Programme for Basic Energy and Conservation in Southern Africa

Table 2

Summary of case studies.

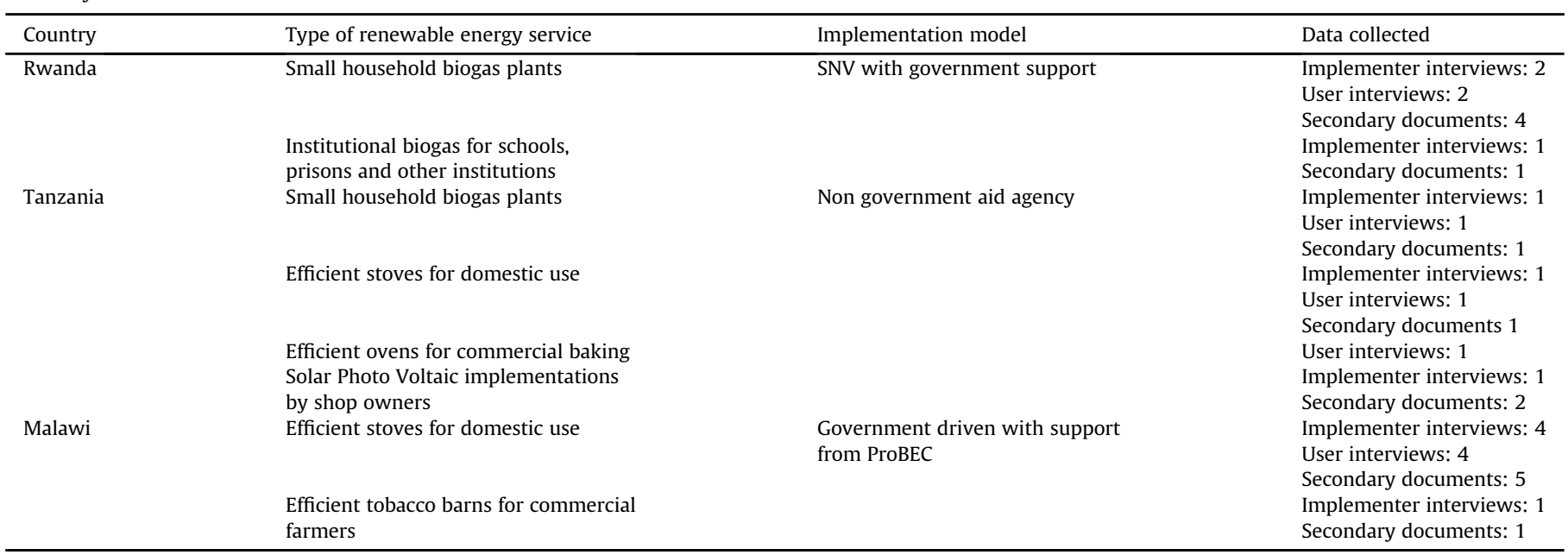


Table 3

Summary of data from eight case studies.

\begin{tabular}{|c|c|c|c|c|c|c|c|c|c|}
\hline \multirow[t]{3}{*}{ Factors } & \multicolumn{5}{|l|}{ RWANDA } & \multicolumn{4}{|l|}{ TANZANIA } \\
\hline & \multicolumn{3}{|c|}{ Domestic biogas } & \multicolumn{2}{|c|}{ Institutional biogas } & \multicolumn{3}{|l|}{ Biogas } & \multirow{2}{*}{$\frac{\text { Solar }}{\text { Interviews }}$} \\
\hline & Interviews & Documents & Observation & Interviews & Documents & Interviews & Documents & Observation & \\
\hline \multicolumn{10}{|c|}{ Technology factors } \\
\hline $\mathrm{T} 1$ & $\sqrt{ }$ & $\sqrt{ }$ & $\sqrt{ }$ & $\sqrt{ }$ & $\sqrt{ }$ & $\sqrt{ }$ & $\sqrt{ }$ & $\sqrt{ }$ & $\sqrt{ }$ \\
\hline $\mathrm{T} 2$ & $\sqrt{ }$ & $\sqrt{ }$ & $\sqrt{ }$ & & $\sqrt{ }$ & $\sqrt{ }$ & $\sqrt{ }$ & $\sqrt{ }$ & $\sqrt{ }$ \\
\hline \multicolumn{10}{|c|}{ Site selection factors } \\
\hline SS1 & $\sqrt{ }$ & $\sqrt{ }$ & $\sqrt{ }$ & & $\sqrt{ }$ & $\sqrt{ }$ & & $\sqrt{ }$ & $\sqrt{ }$ \\
\hline SS2 & $\sqrt{ }$ & $\sqrt{ }$ & & & $\sqrt{ }$ & $\sqrt{ }$ & $\sqrt{ }$ & & $\sqrt{ }$ \\
\hline SS3 & $\sqrt{ }$ & $\sqrt{ }$ & & & & & & & $\sqrt{ }$ \\
\hline SS4 & $\sqrt{ }$ & $\sqrt{ }$ & & & & & $\sqrt{ }$ & & $\sqrt{ }$ \\
\hline \multicolumn{10}{|c|}{ Economic/financial factors } \\
\hline E1 & $\sqrt{ }$ & $\sqrt{ }$ & & $\sqrt{ }$ & $\sqrt{ }$ & $\sqrt{ }$ & $\sqrt{ }$ & & $\sqrt{ }$ \\
\hline E2 & $\sqrt{ }$ & $\sqrt{ }$ & & $\sqrt{ }$ & $\sqrt{ }$ & $\sqrt{ }$ & $\sqrt{ }$ & & $\sqrt{ }$ \\
\hline \multicolumn{10}{|c|}{ Achievability by performing organisation } \\
\hline A1 & $\sqrt{ }$ & $\sqrt{ }$ & & $\sqrt{ }$ & $\sqrt{ }$ & $\sqrt{ }$ & & & $\sqrt{ }$ \\
\hline A2 & $\sqrt{ }$ & $\sqrt{ }$ & & & & $\sqrt{ }$ & & & $\sqrt{ }$ \\
\hline A3 & $\sqrt{ }$ & $\sqrt{ }$ & & & $\sqrt{ }$ & $\sqrt{ }$ & $\sqrt{ }$ & & $\sqrt{ }$ \\
\hline \multicolumn{10}{|c|}{ Newly identified factors } \\
\hline N1 & $\sqrt{ }$ & $\sqrt{ }$ & & & & $\sqrt{ }$ & $\sqrt{ }$ & & $\sqrt{ }$ \\
\hline N2 & $\sqrt{ }$ & $\sqrt{ }$ & & & & & $\sqrt{ }$ & & \\
\hline
\end{tabular}

(ProBEC) is a programme started by the Deutsche Gesellschaft fuer Technische Zusammenarbeit (GTZ) in the Southern African Development Community (SADC).

The goal of ProBEC is to ensure that low-income population groups in SADC are enabled to satisfy their energy needs in a social and environmentally sustainable manner and this is done by promoting improved energy solutions through market development and policy support (GTZ, 2009). ProBEC follows a commercial approach actively trains producers to manufacture energy saving cooking devices in order to ensure that a market is developed which will be sustainable once ProBEC funding is no longer available. ProBEC uses results based monitoring to measure the success of projects [29].

ProBEC has several initiatives in Malawi including the promotion of clay stoves, metal efficient stoves and targeting of employers to install efficient stoves for their workers in their homes.

The efficient tobacco barns were developed for small scale farmers in conjunction with the tobacco industry and NGOs in order to address the damage caused to the environment due to the fact that conventional tobacco drying method uses a lot of wood to cure tobacco.

Three sources of evidence where gathered for each case study namely documents, interviews and direct observations. Direct observations were limited to observing the trained individuals that used the equipment, and the guidelines that were supplied, to determine whether training had been successfully completed. Interviews were conducted with both end users and personnel at implementing organisations. Documentation was obtained via the internet and from the personnel of implementing agencies. A detailed database of evidence was drawn up for each case. Each database was then analysed, in pattern manner as advocated by Yin [6], using the theoretical proposition that the factors identified by Barry et al. [18] were the main factors that should be considered when selecting renewable energy technologies in Africa.

\section{Results}

A summary of the data from all the case studies is shown in Table 3. The table lists the abbreviation for each factor as shown in Table 1 in the first column and all the sources of evidence for each case in the first three rows. The tick marks in the table indicate which source of evidence is applicable for the different factors.
The interviews conducted were transcribed. Pattern analysis was used the used to determine whether the interviews and secondary documentation supported the factors that were identified during the Delphi study [30]. A factor was deemed to be applicable if at least half (four) of the interview or documentation data of all eight cases supported the factor. In the interview questionnaires the interviewees were asked to indicate if there were any factors that they wished to add. The newly identified factors were added by at least half of the interviewees and further confirmation was then sought in the secondary documentation.

\section{Discussion}

\subsection{Technology factors}

\subsubsection{T1: Ease of maintenance and support over the life cycle of the technology}

Ease of maintenance and support over the life cycle of the technology was found to be very important in all the examined cases. The main reason for this is that if the technology is not in working condition, the users will simply abandon it and return to their traditional methods [31-33].

Ease of maintenance and support is ensured in the various cases by implementing the following:

Quality installations. Poor quality undermines end user confidence in technology [31-34].

Maintenance plans. Maintenance plans are essential to ensure continued use of renewable energy technology [35-37] as technical support can present a problem if it is not planned from the outset $[23,35]$. Maintenance plans should also address the maintenance funding model to be used [38].

Training of technicians. It is important that local technicians be trained [23,26,35,39-41]. The lack of technical support results in end users losing confidence in the technology [42], the users not getting value for money [27] or that the users have to wait long periods for maintenance [43].

Maintenance training for users. Maintenance training for users is necessary to help users solve and avoid minor technical problems $[23,35]$ and to ensure that users use technology optimally $[32,44]$.

Keeping maintenance simple. Maintenance is mostly done by women and children [36,45]. Maintenance must therefore be kept simple and close to what the people know $[46,47]$. 
Table 3 (continued)

\begin{tabular}{|c|c|c|c|c|c|c|c|c|c|c|}
\hline \multicolumn{6}{|l|}{ TANZANIA } & \multicolumn{5}{|l|}{ MALAWI } \\
\hline \multirow{2}{*}{$\frac{\text { Solar }}{\text { Documents }}$} & \multicolumn{3}{|c|}{ Efficient stoves } & \multicolumn{2}{|c|}{ Efficient ovens } & \multicolumn{3}{|c|}{ Efficient stoves } & \multicolumn{2}{|c|}{ Efficient tobacco barns } \\
\hline & Interviews & Documents & Observation & Interviews & Observation & Interviews & Documents & Observation & Interviews & Documents \\
\hline \multicolumn{11}{|c|}{ Technology factors } \\
\hline$\sqrt{ }$ & $\sqrt{ }$ & & $\sqrt{ }$ & $\sqrt{ }$ & $\sqrt{ }$ & $\sqrt{ }$ & $\sqrt{ }$ & $\sqrt{ }$ & $\sqrt{ }$ & $\sqrt{ }$ \\
\hline$\sqrt{ }$ & $\sqrt{ }$ & & $\sqrt{ }$ & $\sqrt{ }$ & $\sqrt{ }$ & $\sqrt{ }$ & $\sqrt{ }$ & $\sqrt{ }$ & $\sqrt{ }$ & $\sqrt{ }$ \\
\hline \multicolumn{11}{|c|}{ Site selection factors } \\
\hline$\sqrt{ }$ & $\sqrt{ }$ & & $\sqrt{ }$ & $\sqrt{ }$ & & $\sqrt{ }$ & $\sqrt{ }$ & $\sqrt{ }$ & $\sqrt{ }$ & \\
\hline$\sqrt{ }$ & $\sqrt{ }$ & $\sqrt{ }$ & & $\sqrt{ }$ & & $\sqrt{ }$ & $\sqrt{ }$ & & $\sqrt{ }$ & $\sqrt{ }$ \\
\hline$\sqrt{ }$ & & & & & & $\sqrt{ }$ & & & $\sqrt{ }$ & \\
\hline & & & & & & $\sqrt{ }$ & $\sqrt{ }$ & & $\sqrt{ }$ & \\
\hline \multicolumn{11}{|c|}{ Economic/financial factors } \\
\hline$\sqrt{ }$ & $\sqrt{ }$ & $\sqrt{ }$ & & $\sqrt{ }$ & & $\sqrt{ }$ & $\sqrt{ }$ & & $\sqrt{ }$ & \\
\hline & $\sqrt{ }$ & $\sqrt{ }$ & & $\sqrt{ }$ & & $\sqrt{ }$ & $\sqrt{ }$ & & $\sqrt{ }$ & $\sqrt{ }$ \\
\hline \multicolumn{11}{|c|}{ Achievability by performing organisation } \\
\hline$\sqrt{ }$ & $\sqrt{ }$ & & & & & $\sqrt{ }$ & $\sqrt{ }$ & & $\sqrt{ }$ & \\
\hline$\sqrt{ }$ & $\sqrt{ }$ & & & & & $\sqrt{ }$ & $\sqrt{ }$ & & $\sqrt{ }$ & \\
\hline$\sqrt{ }$ & $\sqrt{ }$ & & & & & $\sqrt{ }$ & $\sqrt{ }$ & & $\sqrt{ }$ & \\
\hline \multicolumn{11}{|c|}{ Newly identified factors } \\
\hline$\sqrt{ }$ & $\sqrt{ }$ & & & & & $\sqrt{ }$ & $\sqrt{ }$ & & & \\
\hline & $\sqrt{ }$ & $\sqrt{ }$ & & & & $\sqrt{ }$ & $\sqrt{ }$ & & $\sqrt{ }$ & \\
\hline
\end{tabular}

Adapting the technology to the specific environment. Technology that is implemented in Africa must be robust and easy to handle [48]. Obtaining spares is a large problem in developing countries [26] and thus the technology selection must take into account the availability of local material [49,50] and continued research is required to ensure optimal utilisation of the technology [51].

\subsubsection{T2: Ease of transfer of knowledge and skills to relevant people in Africa}

In general, the simpler the technology selected, the easier the transfer of knowledge and skills to the relevant people in Africa. This is because of the shortage of trained people in Africa in general. The shortage of trained people is most severe in rural areas.

To ensure the proper transfer of skills, the following must be considered:

Stakeholders to train. It is important that the correct target group be selected for each training session [32]. The following target group must be trained: users [35-37,45,47,52] including women [49,51], installers/producers [35,37,47,52], financial institutions [51,52], field facilitators or extension officers [33,53], trainers [31], national government [52] and local government [52].

Methods of skills transfer. The following methods can be used: user manuals [32,34,35,37,54], formal workshops [31,54], informal training during and after installation [36,45], and demonstrations [55]. Regardless, the training must be practical $[32,45]$.

Skills to be transferred to users. Training should include technical aspects of operation and maintenance [48], but should also include topics outside of the technology, as for example, cooking techniques [48] [33,56], slurry application [48], hygiene [48], household management [56] and recipes [53,56].

Skills to be transferred to installers/producers. Installers/producers must be trained in installation [35], manufacture [56], maintenance $[23,35]$, quality control $[34,56]$, pricing [56] marketing $[34,53,56]$ and management $[35,42]$.

Quality of training. High quality training is needed [32]. Skills transfer can be problematic as trainees often do not have the correct initial skills $[42,54,55]$. Training is necessary when implementing renewable energy technologies to ensure that benefits accrue as expected [44].

Formalisation of skills transfer. The transfer of knowledge of renewable energy technologies can be formalised by updating school curricula [34,40,54] and academic curricula [35].

\subsection{Site selection factors}

\subsubsection{SS1: local champion to continue after implementation}

Local champions of renewable energy technologies in Africa are required because much information in rural Africa is communicated by word of mouth as most households do not have access to modern communication technologies or infrastructure. Projects in Africa are often successful in the short term when the donor agencies or NGOs are on site with the implementation, but fail when these agencies leave.

Identification of local champion. Local champions in the case studies varied from households [38,39,43,45,57,58], producers/ installers [31,40,42,53,54,59], donor agencies [32,49] specially selected promoters [34], and partner organisations [47].

Value of the local champion. Local champions are used for social marketing [56]. Demonstration sites are often installed at the houses of the champions and prospective adopters are then brought to these households for demonstrations [45]. It is important that the owners of the demonstration technology are satisfied with the performance of the technology $[37,48,51,58]$. As renewable energy technologies are often new to the areas where they are implemented, innovative individuals who are prepared to take the risk of implementation are required $[48,49]$. Local champions assist in training [32,47], quality control [47], promotion [31,52,58,60], installation [31], service [31], monitoring and supervision [32]. If the local champions are properly trained, they can also assist in conflict resolution [33].

\subsubsection{SS2: adoption by community}

It is important that before a renewable energy project is implemented the capacity in the community be determined. To facilitate adoption by the community the benefits of adoption must be determined and the information must be distributed to the community. Client satisfaction is very important; without this other members of the community will not be willing to adopt a new technology.

Capacity determination. It is important to determine how many households have the capacity to implement the technology [35,51]. Capacity does not necessarily lead to adoption if the cost of the technology is too high [39,57].

Benefits that facilitate adoption. The benefits identified for renewable energy implementations include: smoke reduction 
$[34,37,40]$, time saving for women and children $[27,31,34,36,37$, $40,42,44,48,51,52,54]$, improvement in health [23,26,37,42,48,49, $51,52]$, having light at night [26,45], environmental benefits [23, $27,37,45,51,54]$, financial benefit because of the need to purchase less firewood, kerosene and fertiliser [23,26,27,31,32,34,36,39, $48,55,57,58,61$ ], improvement in health services [42], improved time for cooking and curing [32,50,55] and convenience [51].

Information distribution. It is important that people are made aware of the benefits of the technology to change their attitudes $[52,55,62]$ as negative attitudes can hamper implementation $[46,47]$. If the value of the technology is perceived to be low by the community, adoption will be limited [47]. Awareness campaigns are necessary to ensure that the consumer population can make rational choices about energy [31]. It was found that the higher the education level of the community the better the adoption rate [34].

Client satisfaction. Quality control is important [35] to ensure adoption. Client satisfaction is very important to ensure success [52]. The technology selected must be close to what the people know and involvement by the community is important [63]. The needs of the community must be understood before implementation $[47,53]$.

\subsubsection{SS3: suitable sites ready for pilot studies}

In three of the cases, namely the implementation of institutional biogas in Rwanda, domestic biogas in Tanzania and efficient ovens in Tanzania, no evidence was found that pilot studies are important. However, in all the other cases pilot sites were found to be important. The two issues considered were the selection of pilot sites and the value of pilot sites.

Selection of pilot sites. Pilot sites can be selected using partner organisations that work in the local community [35,47]. The implementation at the selected pilot sites must have high quality of implementation and training [48,51,52]. Public places such as school or health facilities can be used for pilot sites [42,53,54].

Value of pilot sites. Pilot sites can be used for training [35], as part of the promotion campaign [48], iterative development [47,52] [54], and as demonstration plants [40,47,54]. The lessons learnt during the pilot phase can be used to improve future implementation [42].

\subsubsection{SS4: access to suitable sites can be secured}

To secure access to suitable sites, the case study implementations used the following methods: determining the priorities of the population in order to decide what type of technology is the most important; setting of implementation targets; identification of the criteria that a site must meet before the technology can be implemented there; and identification of suitable sites.

Determine priorities of the population. Energy plans and policies can be investigated [49]. It is important to understand the priorities of the population as the population might not understand the benefits of a specific technology [54].

Set implementation targets. Implementation targets can be set in phases $[35,38,54]$. Estimates can be made of the number of possible sites $[37,40,42,64]$.

Identification of sites. Suitable sites can be identified in cooperation with partner organisations $[46,47]$.

\subsection{Economic/financial factors}

\subsubsection{E1: economic development}

The economic development potential of renewable energy is generally twofold, namely, income generation and household savings. The cost of renewable energy technologies in Africa is kept to a minimum, and large profits are not planned for [37]. At national level there is also the potential for income and savings.
Income generation. Income is generated from being involved in installing [35,40,49,54], producing [33,53,56,59,60,62,63], maintaining $[49,54]$ or providing training for the renewable energy technology [53], or by utilising the product of the renewable energy technology to generate income. Most of the case study implementations focussed on creating a continuous market or sector for the renewable energy technology implemented which contributes to job creation $[26,27,31,34,40,46-49,51-54,59,63]$.

Cost and time savings. Households and institutions save money in that they no longer need to buy wood, charcoal, kerosene, candles, batteries and where available, electricity [23,26,27,34,35,35, $39-41,44,48,49,51,52,54,56,58,59,61]$. Women and children save time as they no longer need to gather as much wood $[26,31$, $33,40,48,55,56]$ and this saved time can be used for economic activities [26,31,55].

National income and savings. Countries benefit from renewable energy projects as carbon credits $[37,48]$ can be sold and less expensive energy sources need to be imported [51]. Countries further benefit as the renewable energy technology implementations in the case studies also contribute to skills development which is a priority in most African countries [27,49,51,53,54,57,63].

\subsubsection{E2: availability of finance}

Availability of finance was cited in most of the interviews and documentation as the main stumbling block to the implementation of renewable energy technologies in Africa, as the rural population in Africa is very poor, some renewable energy technologies have a high initial installation cost, and the availability of firewood [31] means that the rural population does not see the value of renewable energy technologies for most of their energy needs.

Payment methods. The main ways of payment were found to be cash [39,56], materials [39], produce barter [56] or labour [39,53]. Cash is normally raised by selling produce $[36,45,48]$ or employment $[43,48]$. The savings achieved using renewable energies can be used to pay off loans $[23,34]$. Some of the institutional biogas facilities in Rwanda were funded by donors [41].

Finance methods. The methods used by the programmes to make finance available include subsidies [31,35,49,51,52,59], credit loans $[26,31,36-38,42,47-49,51,52,54,57,60]$ and the giving of the renewable energy technology to the population for free $[34,46,56]$ or on loan [63]. Subsidies are provided by donor agencies $[32,35,38]$ or government [35]. The government can subsidise renewable energy technology by providing financing or by removing duties and taxes $[31,63]$ on the technology. The rural poor do not normally have access to loans [39] and for this reason the implementing agency must negotiate with banks for favourable rates and payment periods $[31,37,38,42,48,49,52,54,57]$. One of the problems that have not yet been solved is the provision of finance to households with seasonal income [40,42,54]. Subsidies are carefully managed, in some cases subsidy is paid directly to the bank $[37,38]$ and in other cases directly to the installer.

\subsection{Achievability by performing organisation}

\subsubsection{A1: business management}

Project management was identified during the focus group [4] and Delphi study [5] as a necessary skill for the performing organisation. During the case studies, however, it transpired that the skills required by the performing organisation are rather business management skills. In some of the case studies business management training $[40,41]$ had been implemented whilst in other case studies is had been identified as an important requirement. The lack of business skills was identified as a reason why some businesses failed [54]. 
Business management skills required. The following business management skills were found to be important during the case studies: market development [35], marketing [33,34,47,51,54,56], management [35,37,47,57], personnel management [51], business development [38], price determination [34], financial management and organisational management [38,51,57].

Transfer of business management skills. Skills are transferred through formal training [38] and by doing the work with assistance and support $[37,49]$.

Where skills are lacking. If the performing organisation does not have the required business management skills, the donor organisation or the government can help the performing organisation especially in terms of marketing and market development $[53,59,60]$.

\subsubsection{A2: financial capacity}

Financial capacity refers to the capacity of the performing organisation to finance the components and materials required for technology implementation. Especially when the performing organisation first starts up financial capacity can hinder the organisation from succeeding. With capital intensive technologies such as solar photovoltaics it was found that some performing organisations stop supplying the technology because of financial constraints [42,64].

Methods of dealing with financial capacity. The following methods were implemented to ensure that the performing organisations would have the financial capacity to implement the technologies: financial model of the project set up in such a way that the performing organisation has minimum capital outlay $[35,37,40,47]$, subsidies $[42,48,49,51,52,64]$, training to cluster work [37] and using technology that has very little capital outlay $[32,53,54,59,60]$.

\subsubsection{A3: Technological capacity}

Technological capacity of the performing organisation is of paramount importance [34] as poor quality products give renewable energy technologies a bad name in the community [33,34]. Technological capacity was found to be a problem as skills in Africa in general are problematic [31,42,54,64]. In the case studies, the following methods were utilised to overcome these difficulties:

Quality assurance. Quality control is enforced $[32,52,56]$ and is done by the implementing organisations [47,48,51,59] through monitoring and evaluation [51,56]. Subsidies are linked to the quality control system $[48,49,52]$.

Training. Training involves installation [23,26,37,54,57] and maintenance training $[23,26,54,57]$. Refresher courses [35,48,60] are offered to correct mistakes and also to introduce adaption of processes [32]. Training installers on quality is also important [51].

Support. Support is given by the programme implementers in the form of technical backstopping $[32,35,47,59]$ and supervision for a time during installation [48].

Regulation. Regulation is twofold, namely certification or registration of installers $[23,32,35,48]$ and dictating standards [51].

Technology selection. Technology was selected so that it could be installed by semi-skilled workers [49].

Client support. Clients were given technical guarantees $[32,48,52]$ and after sales service $[23,48,52]$.

\subsection{Newly identified factors}

The purpose of the case study was not only to confirm the factors identified through the previous research efforts, but also to determine whether additional factors were also important for the case study. These factors were identified by asking the interviewees at the end of the interview to identify other factors which were important and then confirming the importance from the secondary data.
Table 4

Thirteen final factors to consider for sustainable, renewable energy technology selection in Africa.

\begin{tabular}{ll}
\hline Abbreviation & Description \\
\hline T & Technology factors \\
T1 & $\begin{array}{l}\text { Ease of maintenance and support over the life cycle } \\
\text { of the technology } \\
\text { Ease of transfer of knowledge and skills to relevant } \\
\text { T2 }\end{array}$ \\
& people in Africa \\
SS & Site selection factors \\
SS1 & Local champion to continue after implementation \\
SS2 & Adoption by community \\
SS3 & Suitable sites ready for pilot studies \\
SS4 & Access to suitable sites can be secured \\
E & Economic/financial factors \\
E1 & Economic development \\
E2 & Availability of finance \\
A & Achievability by performing organisation \\
A1 & Business management \\
A2 & Financial capacity \\
A3 & Technological capacity \\
N & Newly identified factors \\
N1 & Government support \\
N2 & Environmental benefits \\
\hline
\end{tabular}

\subsubsection{N1: government support}

In the cases examined, governmental support was stated as being important whether it was available for the specific project or not. Acceptance by the government of the specific renewable energy programme is important [37,63] as was one of the lessons learnt in the solar photo voltaic implementation in Tanzania [54]. The government has to support policies to save the environment by banning the cutting of trees for example, and by ensuring that alternatives are available for the population $[40,58]$.

Governmental support is required in a number of areas including: regulations such as strategies [51], policies [26,38,64] and legislation [31,39]; standards [38]; reduction in or elimination of duties and taxes [42]; funding or subsidies [31,40,42,54]; licencing of technologies [63]; setting up energy regulation agencies [64] [48]; partnering with donor organisations [48]; building technical capacity [31,38,42]; public awareness [31]; market promotion [31]; forest law enforcement [31,39,54]; health and safety; and monitoring and evaluation [31].

\subsubsection{N2: environmental benefits}

Environmental benefits were found to be important largely during the implementer interviews and in the supporting documents.

The main environmental benefit of renewable energy technology is that it halts deforestation [27,31,32,34,35,39,47,47-49, $51,56,58,59,63]$. Other benefits include the release of fewer greenhouse gasses [27,31,48,49,51], protection of fragile ecosystems $[27,31]$, as well as halting soil erosion [27,34,49], desertification [27] and fresh water pollution $[31,34,49]$.

\section{Conclusions}

The case studies conducted in three developing sub-Saharan African countries have confirmed that the propositions by Barry et al. [17,18] are important. The wording of one of the factors has changed and two new factors have also been added to the list. The thirteen final factors identified during the case studies are shown in

Table 4 , and have been described in this paper.

The authors believe that the use of these thirteen factors in the selection of technologies for energy projects would contribute significantly towards the long-term sustainability of renewable energy endeavours in Africa. 


\section{References}

[1] Energy sector management assistance program. Technical paper: energy sector reform and pattern of poor: Energy use and supply a four country study. Botswana, Ghana: Honduras and Senegal; 2006. vol. 2008.

[2] United Nations Energy Agency. Energy for sustainable development: policy options for Africa; 2007. vol. 2008.

[3] Dunmade I. Indicators of sustainability: assessing the suitability of a foreign technology for a developing economy. Technology in Society 2002; vol. 24: $461-71$.

[4] Ruder KA, Pretorius MW, Maharaj BT. A technology selection framework for the telecommunications industry in developing countries. In: ICC 2008 Proceedings, 2008, pp. 5490.

[5] International Environmental Technology Centre. Technology transfer: the seven "C"s for the successful transfer and uptake of environmentally sound technologies; 2004. vol. 2010.

[6] Teitel S. On the concept of appropriate technology for less industrialised countries. Technological Forecasting and Social Change 1978;vol. 11: 349-69.

[7] Cherni JA, Dyner I, Henao F, Jaramillo P, Smith R, Font RO. Energy supply for sustainable rural livelihoods. A multi-criteria decision-support system. Energy Policy 2007; vol. 35(3):1493-504.

[8] Haung L, Lu W, Li X. Study on emerging technology selection and evaluation by technology foresight and fuzzy consistent matrix. In: PICMET 2009 Proceedings, 2009, pp. 441.

[9] Chataway J, Smith J, Wield D. Science and technology partnerships and poverty alleviation in Africa. International Journal of Technology Management and Sustainable Development 2006;vol. 5:103-23.

[10] Torkkeli M, Tuominen M. Use of GDSS in technology selection: Experience and findings. In: Proceedings of the 34th Hawaii International Conference on System Sciences, 2001, p. 1.

[11] Ebohon OJ, Field BG, Ford R. Institutional deficiencies and capacity building constraints: the dilemma for environmentally sustainable development in Africa. International Journal of Sustainable Development \& World 1997; vol. 4: 204-13.

[12] Prasad G, Visagie E. Renewable energy technologies for poverty alleviation. Initial assessment report: south Africa; 2005. vol. 2007.

[13] Jimenez BTx, Alvear A, AlYabes A, Olaoye A. Technology assessment and selection of renewable energy sources in the galapagos islands - ecuador. In: PICMET 2007 Proceedings, 2007, p. 2509.

[14] Nguyen KQ. Alternatives to grid extension for rural electrification: Decentralized renewable energy technologies in Vietnam. Energy Policy 2007;vol. 35:2579-89.

[15] Cherni JA, Hill Y. Energy and policy providing for sustainable rural livelihoods in remote locations - The case of Cuba. Geoforum 2009;vol. 40:645-54. 7.

[16] Egmond C, Jonkers R, Kok G. A strategy and protocol to increase diffusion of energy related innovations to the mainstream of household associations. Energy Policy 2006;vol. 34:4042-9.

[17] Barry M, Steyn H, Brent AC. The use of the focus group technique in management research: the example of renewable energy technology selection in Africa. Journal of Contemporary Management 2009;vol. 6:229-40.

[18] Barry ML, Steyn H, Brent AC. Determining the most important factors for sustainable energy technology selection in Africa. South African Journal of Industrial Engineering Nov 2009;vol. 20:33-51.

[19] Yin RK. Case study research: Design and methods. In: Applied social research method Series, 3rd ed. Anonymous Thousand Oaks. California: SAGE Publications; 2003. vol. 5.

[20] CIA. The world factbook - Rwanda. vol. 2010; April 2010

[21] MINITERE. National adaptation programs of action to climate change (NAPA). vol. 2008; December 2006.

[22] Project brief NDBP. National domestic biogas program; 2008. Rwanda.

[23] Munyehirwe A, Kabanda P. Performance assessment institutional biogas systems in rwanda: Report. Kigali: IBC and GTZ; 2008.

[24] CIA. The world Factbook - Tanzania; 22 April 2010. vol. 2010

[25] Tanzania Ministry of energy and minerals; 2009. vol. 2009, Not specified.

[26] Mwakaje AG. Dairy farming and biogas use in Rungwe district, South-west Tanzania: a study of opportunities and constraints. Renewable and Sustainable Energy Reviews 2008;vol. 12:2240-52.

[27] TaTEDO. About TaTEDO; 2009. vol. 2010, Not specified.

[28] CIA. The world Factbook - Malawi; 21 April 2010. vol. 2010.

[29] GTZ. ProBEC saving energy for a better future; 2009. vol. 2009, Not stated.

[30] Barry M. Contributions to the Theory and Practice of technology selection: The Case of Projects to Ensure a Sustainable Energy Base for Africa; 2010.
[31] PAESP. Promotion of alternative energy sources project (PAESP). Malawi: Department of energy affairs; 2006.

[32] DeGabriele J, Msukwa A. ProBEC study on the impact of rocket stoves in school kitchens. Lilongwe, Malawi: ProBEC; 2007.

[33] Nyengo K. Assessment of durability of portable clay stoves. Malawi: ProBEC; 2006.

[34] Brinkmann V. Impact assessment at local level: Experiences from malawimulanje district. Malawi: ProBEC, GTZ; 2004.

[35] Uwizeye JC. Interview: Implementer interview, Domestic biogas Rwanda - 22 September, 2008.

[36] Gervais G. Interview: End-user interview, Domestic biogas Rwanda - 23 September, 2008

[37] Dekelver G. Interview: Implementer interview, Domestic biogas Rwanda - 22 September, 2008.

[38] Banks DI, Steel K, Kibazohi O. Transformation of rural photovoltaic (PV) market in Tanzania URT/03/G31/A/1 G/99; 15 March 2007. Mid-Term evaluation, final Report, vol. 2009.

[39] Kidini MA. Interview: End-user questionnaire, Domestic biogas Tanzania - 24 September, 2008.

[40] Nzali A, Mkunda T. Interview: Implementer questionnaire, Efficient stoves Tanzania - 24 September, 2008

[41] Uwizeye JC. Interview: Implementer interview, Institutional biogas Rwanda 22 September, 2008.

[42] Mwanza. vol. 2010, Not specified.

[43] Exaud B. Interview: End-user questionnaire, Efficient ovens Tanzania - 25 September, 2008

[44] Gondwe V. Houses baseline situation for limbulit, landerdello and esparanza tea estates in mulanje district for biomass energy conservation technologies. Malawi: SADC, ProBEC, GTZ; 2007.

[45] Speciose N. Interview: End-user interview, Domestic biogas Rwanda - 23 September, 2008.

[46] Vutuza P. Interview: End-user questionnaire, efficient stoves in Malawi - 27 September, 2008.

[47] Sukasuka T. Interview: Implementer questionnaire, efficient stoves in Malawi - 27 September, 2008.

[48] Huba EM, Paul E. National domestic biogas program rwanda baseline study report. Kigali, Rwanda: MINIFRA; 2007.

[49] Dekelver G, Ruzigana S, Lam J. Report on the feasibility for a biogas support programme in the republic of rwanda. Kigali, Rwanda: SNV; 2005.

[50] Scott P. Development of improved tobacco curing barn for small holder farmers in southern africa: 2007-2008 trials at nature's gift testing facility. Lilongwe, Malawi: Trent Bunderson /TLC and Imperial Tobacco; 2008.

[51] Dekelver G, Ndahimana A, Ruzigana S. Implementation plan national programme on domestic biogas in rwanda. Kigali, Rwanda: SNV, Netherlands Development Organisation and MININFRA; 2006.

[52] Bajgan S, Shakya IS. A successful model of public private partnership for rura household energy supply. Kigali, Rwanda: SNV; 2005.

[53] Gondwe V, Khonje T, Sukasuka T. Interview: Implementer questionnaire, efficient stoves in Malawi - 27 September, 2008.

[54] Nzali A, Mkunda T. Interview: Implementer questionnaire, Solar energy Tanzania - 24 September, 2008.

[55] Ndiwo L. Factors affecting adoption of a fireless (retained heat) cooker by households: a case study of thuchila EPA in mulanje district. Lilongwe, Malawi: GTZ; 2008.

[56] Malinski B. Impact assessment of chitetezo mbaula - improved household firewood stove in rural malawi. Malawi: GTZ; 2008.

[57] Elisa FA. Interview: End-user questionnaire, Domestic biogas Tanzania - 25 September, 2008.

[58] Kidini MA. Interview: End-user questionnaire, Efficient stoves Tanzania - 24 September, 2008.

[59] Chilewe W. Interview: End-user questionnaire, Efficient stoves Malawi - 27 September, 2008.

[60] Mwalimu E, Njwambo L, Nchenga E, Waisen A, Nathenwe T, Timu E, Nazambe J. Interview: End-user questionnaire, Efficient stoves Malawi - 27 September, 2008.

[61] Chipyoza K. Interview: End-user questionnaire, Efficient stoves Malawi - 27 September, 2008.

[62] Banda W. Interview: End-user questionnaire, Efficient stoves Malawi - 28 September, 2008.

[63] Chitenje H. Interview: Implementer questionnaire, efficient stoves in Malawi 26 September, 2008.

[64] Department of energy affairs. Promotion of alternative energy sources project (PAESP). Lilongwe, Malawi: Malawi department of energy affairs; 2006. 